\title{
PEDIKULOSIS ANAK DI SALAH SATU PERUMAHAN DI BEKASI
}

\author{
Rika Suhesti ${ }^{1}$, Intan Kurniawati Pramitaningrum ${ }^{2 *}$ \\ 1. Program Studi DIII Analis Kesehatan, STIKes Mitra Keluarga, Bekasi-Indonesia \\ 2. Program Studi DIII Analis Kesehatan, STIKes Mitra Keluarga, Bekasi-Indonesia
}

*Korespondensi: Intan Kurniawati Pramitaningrum | STIKes Mitra Keluarga | intankp@gmail.com

\begin{abstract}
Abstrak
Pendahuluan: Pedikulosis adalah iritasi kulit yang disebabkan oleh spesies kutu rambut Pediculus capitis. Pediculus capitis menyerang anak terutama di lingkungan yang padat dan akibat aktivitas bermain bersama. Penelitian ini bertujuan untuk mengetahui angka kejadian pediculosis capitis di salah satu perumahan di Bekasi.

Metode Penelitian ini merupakan penelitian deskriptif kualitatif dengan desain crossectional. Pemeriksaan kutu rambut dilakukan pada 44 responden anak-anak pada rentang usia 3-12tahun. Penelitian dilakukan pada 10-15 Februari 2019 di salah satu perumahan di Cibitung Bekasi.

Hasil: Hasil penelitian mengenai pedikulosis pada anak usia 3-12 tahun yang positif mengalami kejadian pedikulosis yaitu 28 anak perempuan dengan persentase $85 \%$ dari 33 anak perempuan dan 4 anak laki-laki dari 11 anak laki-laki dengan persentase $36 \%$.

Kesimpulan: Kejadian pedikulosis lebih tinggi dialami oleh anak perempuan dibandingkan dengan anak laki-laki karena berkaitan dengan faktor resiko seperti jenis rambut, penggunaan handuk secara bersama, penggunaan sampo saat keramas, riwayat keluarga mengalami kutu rambut, rutinitas mengganti sprei tempat tidur seminggu sekali, tidur ditempat tidur secara bersama, menggunakan sisir bersama dan penggunaan aksesoris secara bersama.
\end{abstract}

Kata Kunci: Anak, kutu, pedikulosis, lingkungan,Bekasi.

Diterima 14 Oktober 2020; Accepted 30 Desember 2020

\section{PENDAHULUAN}

Pedikulosis merupakan iritasi kulit yang disebabkan oleh spesies Pediculus humanus capitis, Pediculus corporis, dan Pediculus pubis (Natadisastra \& Agoes, 2014). Iritasi kulit akibat pediculosis sering terjadi, serta tingkat kejadiannya dinyatakan cukup tinggi di negara berkembang (Hadidjaja \& Margono, 2011). Prevalensi anak perempuan lebih tinggi dibandingkan laki - laki yang terkena pedikulosis karena perempuan mayoritas memiliki rambut yang panjang sehingga lebih susah untuk dibersihkan dan perempuan lebih suka bertukar aksesoris rambut (Wolff \& Richard, 2009).

Centers for Disease Control and Prevention (CDC) pada tahun 2017 menyatakan bahwa infestasi Pediculus humanus capitis tersebar diseluruh dunia dengan angka kejadian terbanyak pada anak usia 3 sampai 11 tahun. Penelitian pediculosis capitis di Malaysia dari 18 sekolah dasar sebesar 1.336 anak usia 712 tahun, pada anak perempuan 28,4\% positif dan anak laki-laki 3,7\% yang positif (Tohit et al., 2017). Penelitian pedikulosis di Meksiko pada anak sekolah dasar di pedesaan tahun 2011 usia 7-12 tahun dari 57 anak diperoleh hasil yaituanak perempuan tingkat kejadian Pediculosis capitis sebanyak 11\% dan laki-laki 8\% (Saide et al., 2011). Kejadian pedikulosis pada tahun 2015 di Indonesia sekitar 15\% (Eliska, 2015). Penelitian sebelumnya dari beberapa tempat di Indonesia tingkat kejadian pedikulosis dari 3 Panti Asuhan di kota Pekanbaru yaitu Panti Asuhan X, Y, dan Z dari 127 sampel usia 1-18 tahun. Pada Panti Asuhan X dari 30 sampel anak yang positif pedikulosis $15 \%$ anak perempuan dan $10 \%$ anak laki-laki, Pada Panti Asuhan Y dari 57 sampel anak yang positif pedikulosis 17\% anak perempuan dan 3\% anak laki-laki, dan pada Panti Asuhan $\mathrm{Z}$ dari 40 sampel anak yang positif pedikulosis $22 \%$ anak perempuan dan $6 \%$ anak lakilaki (Maryanti et al., 2018). Kejadian pedikulosis di Pelesiran Kota Bandung dari 84 sampel anak usia 7-12 tahun, pada anak perempuan $84,85 \%$ positif dan laki-laki $41,18 \%$ positif pedikulosis (Nurlatifah et al., 2017).

Pedikulosis dapat menyebabkan iritasi, luka, dan anemia pada penderita. Pedikulosis dapat menimbulkan masalah sosial seperti dikucilkan dan malu. Pedikulosis dapat menyebabkan kurangnya kualitas tidur, menimbulkan ketidak nyamanan, dan mengganggu konsentrasi belajar (Haghi et al., 2014). Faktor yang mempengaruhi penyebaran pedikulosis diantaranya jenis kelamin, frekuensi cuci rambut, penggunaan sisir atau aksesoris rambut bersama, penggunaan alas atau tempat tidur bersama, panjang rambut, dan jenis rambut (Lukman et al., 2018).

Pediculus humanus capitis dapat bergerak dengan cepat serta mudah berpindah dari satu hospes ke 
hospes lain. Penularannya melalui kontak langsung antara kepala atau melalui pemakaian barang-barang secara bersama seperti sisir, bantal, kerudung, handuk dan tidur bersama (Aditya et al., 2013). Cibitung merupakan daerah Bekasi yang memiliki kepadatan penduduk yang tinggi. Pada salah satu perumahan Cibitung Bekasi terdapat banyak anak usia 3-12 tahun dan belum pernah dilakukan penelitian sebelumnya.

\section{METODE}

Jenis penelitian yang digunakan adalah deskriptif kualitatif dengan desain cross sectional pada anakanak usia 3-12 tahun di salah satu perumahan Cibitung Bekasi. Penelitian dilakukan tanggal 10-15 Februari 2019. Jumlah responden adalah 44 orang. Pembuatan sediaan awetan Pediculus humanus capitis dilakukan di Laboratorium STIKes Mitra Keluarga. Alat yang digunakan dalam penelitian ini adalah handscoon, sisir serit, plastik, wadah, kaca preparat, cover glass, pipet tetes, dan mikroskop. Bahan yang digunakan dalam penelitian ini adalah larutan $\mathrm{KOH} 5 \%, 10 \%, 15 \%, 20 \%$, aquadest, alkohol 30\%, 50\%, 96\%, alkohol absolute, xylol, dan entelan.

\section{Informed consent dan pengambilan sampel}

Responden mengisi informed consent dibantu oleh wali ataupun peneliti. Responden diperiksa menggunakan sisir serit satu kali pakai. Pengambilan kutu dengan menyisir dan melakukan 3 kali pengulangan pada bagian pelipis, tengkuk dan telinga responden serta dicari secara manual. Responden dinyatakan positif apabila ditemukan telur, nimfa, dan kutu dewasa dan negatif apabila tidak ditemukannya telur, nimfa, dan kutu dewasa. Telur, nimfa, dan kutu dewasa di identifikasi di bawah mikroskop perbesaran $4 \mathrm{x}$.

\section{Identifikasi dan pembuatan preparat awetan}

Sampel yang diperoleh selanjutnya diidentifikasi berdasarkan morfologi bawah mikroskop perbesaran 4x. Pediculus humanus capitis yang telah diidentifikasi selanjutnya direndam dalam larutan $\mathrm{KOH}$ menggunakan pengenceran bertingkat dengan konsentrasi 5\%, 10\%, 15\%,dan $20 \%$ selama 24 jam, kemudian dibilas dengan aquadest. Pediculus huumanus capitis kemudian dimasukan ke dalam larutan alkohol 30\% selama 15 menit dengan melakukan 3 kali pergantian larutan alkohol 30\%, kemudian diangkat dari larutan alkohol untuk dilakukan pemipihan dengan 2 kaca preparat untuk mengeluarkan cairan dalam tubuhnya. Pediculus humanus capitis selanjutnya direndam menggunakan larutan alkohol 50\% dan 96\%, kemudian Pediculus humanus capitis direndam dengan larutan alkohol absolute selama 15 menit. Pediculus humanus capitis kemudian direndam dengan larutan xylol selama 15 menit, proses terakhir diletakan diatas kaca preparat dan diberi entelan serta ditutup dengan cover glass.

\section{HASIL}

Responden berusia 3-12 tahun dengan jumlah anak laki-laki 11 dan anak perempuan 33 anak. Pediculus humanus capitis betina dewasa yang teramati memiliki ukuran panjang 115 mikrometer dan lebar 29 mikrometer. Pediculus humanus capitis jantan karena pada bagian posterior menonjol keluar. Pediculus humanus capitis memiliki 3 pasang kaki yang ujungnya terdapat kuku cakar atau claw berfungsi untuk melekat pada rambut hospes, memiliki antena yang terdiri dari 5 segmen, satu mulut dan memiliki satu pasang mata yang kecil terdapat di belakang antena. Fase nimfa yang teramati memiliki ukuran panjang 40 mikrometer dan lebar 11 mikrometer. Telur Pediculus humanus capitis memiliki bentuk yang oval, panjangnya $0,8 \mathrm{~mm}$ dan lebar $0,3 \mathrm{~mm}$, mempunyai kapsul, pada bagian anteriornya pipih dan terdapat saluran kecil untuk udara (Irianto, 2013).

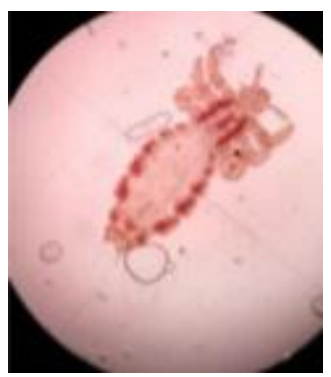


Gambar 1. Awetan Pediculus humanus capitis

Berdasarkan Gambar 2. menunjukan bahwa prevalensi anak-anak di salah satu perumahan Cibitung Bekasi usia 3-12 tahun yang positif adalah 32 (73\%) dan yang tidak mengalami kejadian pedikulosis adalah $12(27 \%)$.

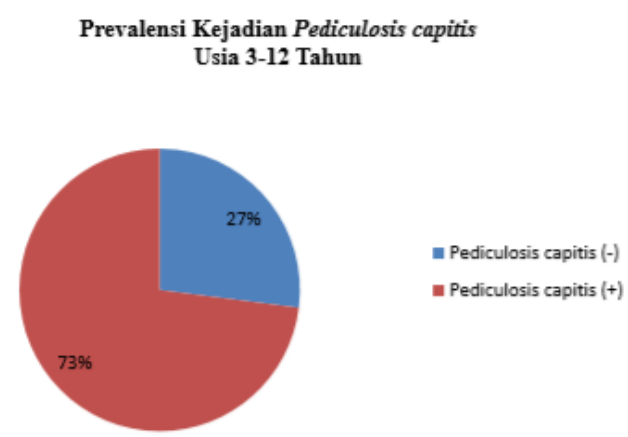

Gambar 2. Prevalesnis pedikulosis di salah satu perumahan di Cibitung Bekasi.

Tabel 1.Kejadian pedikulosis pada anak perempuan dan laki-laki di salah satu perumahan Cibitung Bekasi.

\begin{tabular}{cccccccc}
\hline \multirow{2}{*}{$\begin{array}{c}\text { Jenis } \\
\text { Kelamin }\end{array}$} & \multicolumn{3}{c}{ Kejadian Pediculosis capitis } & & \multicolumn{2}{c}{ Jumlah } \\
\cline { 2 - 5 } & \multicolumn{2}{c}{ Positif } & \multicolumn{2}{c}{ Negatif } & & \\
\hline Perempuan & 28 & $85 \%$ & 5 & $15 \%$ & 33 & $100 \%$ \\
Laki-laki & 4 & $36 \%$ & 7 & $64 \%$ & & 11 & $100 \%$
\end{tabular}

Berdasarkan Tabel. 1 menunjukan bahwa prevalensi pedikulosis pada anak perempuan adalah $85 \%$ dari 33 total anak dan pada anak laki-laki 36\% dari 11 total anak laki-laki. 
Tabel 2. Faktor resiko pedikulosis

\begin{tabular}{|c|c|c|c|c|c|c|c|c|c|c|c|}
\hline \multirow{2}{*}{\multicolumn{2}{|c|}{ Karakteristik }} & \multirow{3}{*}{$\begin{array}{c}\begin{array}{c}\text { Jumlah } \\
\text { P }\end{array} \\
29\end{array}$} & \multicolumn{2}{|c|}{ Positif } & \multicolumn{2}{|c|}{ Negatif } & \multirow{2}{*}{$\underset{\text { L }}{\text { Jumlah }}$} & \multicolumn{2}{|c|}{ Positif } & \multicolumn{2}{|c|}{ Negatif } \\
\hline & & & $\mathbf{n}$ & $\%$ & $\mathrm{n}$ & $\%$ & & $\mathrm{n}$ & $\%$ & $\mathbf{n}$ & $\%$ \\
\hline \multirow[b]{2}{*}{$\begin{array}{c}\text { Jenis } \\
\text { Rambut }\end{array}$} & Lurus & & 27 & 93 & 2 & 7 & 5 & 2 & 40 & 3 & 60 \\
\hline & Keriting & 4 & 1 & 25 & 3 & 75 & 6 & 2 & 33 & 4 & 67 \\
\hline \multirow{2}{*}{$\begin{array}{l}\text { Ukuran } \\
\text { Rambut }\end{array}$} & Panjang & 25 & 23 & 92 & 2 & 8 & 2 & 1 & 50 & 1 & 50 \\
\hline & Pendek & 8 & 5 & 62 & 3 & 38 & 9 & 3 & 33 & 6 & 67 \\
\hline \multirow{2}{*}{$\begin{array}{c}\text { Penggunaan } \\
\text { Handuk } \\
\text { secara } \\
\text { bersama } \\
\end{array}$} & Ya & 24 & 21 & 88 & 3 & 12 & 7 & 3 & 43 & 4 & 57 \\
\hline & Tidak & 9 & 7 & 78 & 2 & 22 & 4 & 1 & 25 & 3 & 74 \\
\hline \multirow[b]{2}{*}{$\begin{array}{c}\text { Keramas } \\
\text { Seminggu } \\
>2 \mathrm{x}\end{array}$} & Ya & 13 & 12 & 92 & 1 & 8 & 8 & 1 & 13 & 7 & 87 \\
\hline & Tidak & 20 & 16 & 80 & 4 & 20 & 3 & 3 & 100 & 0 & 0 \\
\hline \multirow{2}{*}{$\begin{array}{c}\text { Keramas } \\
\text { Menggunakan } \\
\text { Sampo }\end{array}$} & $\mathrm{Ya}$ & 7 & 2 & 29 & 5 & 71 & 7 & 2 & 29 & 5 & 71 \\
\hline & Tidak & 26 & 26 & 100 & 0 & 0 & 4 & 2 & 50 & 2 & 50 \\
\hline \multirow{2}{*}{$\begin{array}{c}\text { Keluarga } \\
\text { pernah } \\
\text { mengalami } \\
\text { kutu rambut }\end{array}$} & $\mathrm{Ya}$ & 23 & 19 & 83 & 4 & 17 & 6 & 1 & 17 & 5 & 83 \\
\hline & Tidak & 10 & 9 & 90 & 1 & 10 & 5 & 3 & 60 & 2 & 40 \\
\hline \multirow{2}{*}{$\begin{array}{c}\text { Mengganti } \\
\text { sprei tempat } \\
\text { tidur sekali } \\
\text { seminggu }\end{array}$} & $\mathrm{Ya}$ & 5 & 3 & 60 & 2 & 40 & 6 & 1 & 17 & 5 & 83 \\
\hline & Tidak & 28 & 25 & 89 & 3 & 11 & 5 & 3 & 60 & 2 & 40 \\
\hline \multirow{2}{*}{$\begin{array}{c}\text { Alas tidur } \\
\text { atau tempat } \\
\text { tidur secara } \\
\text { bersama }\end{array}$} & Ya & 18 & 16 & 89 & 2 & 11 & 9 & 3 & 33 & 6 & 67 \\
\hline & Tidak & 15 & 12 & 80 & 3 & 20 & 2 & 1 & 50 & 1 & 50 \\
\hline \multirow{2}{*}{$\begin{array}{l}\text { Penggunaan } \\
\text { sisir bersama }\end{array}$} & $\mathrm{Ya}$ & 29 & 25 & 86 & 4 & 14 & 7 & 3 & 43 & 4 & 57 \\
\hline & Tidak & 4 & 3 & 75 & 1 & 25 & 4 & 1 & 25 & 3 & 75 \\
\hline \multirow{2}{*}{$\begin{array}{c}\text { Penggunaan } \\
\text { aksesoris } \\
\text { bersama }\end{array}$} & $\mathrm{Ya}$ & 21 & 19 & 90 & 2 & 10 & 2 & 0 & 0 & 2 & 100 \\
\hline & Tidak & 12 & 9 & 75 & 3 & 25 & 9 & 4 & 44 & 5 & 56 \\
\hline \multirow{2}{*}{$\begin{array}{c}\text { Pernah } \\
\text { memakai obat } \\
\text { kutu rambut }\end{array}$} & $\mathrm{Ya}$ & 15 & 13 & 87 & 2 & 13 & 6 & 2 & 33 & 4 & 67 \\
\hline & Tidak & 18 & 15 & 83 & 3 & 17 & 5 & 2 & 40 & 3 & 60 \\
\hline
\end{tabular}

\section{PEMBAHASAN}

Penelitian ini sesuai dengan penelitian sebelumnya yang menyatakan bahwa pedikulosis adalah penyakit menular yang dipengaruhi oleh lingkungan dan perilaku. Lingkungan padat penghuni seperti di pondok pesantren (Lukman et al., 2018). Tingginya angka kejadian pediculosis capitis akan menimbulkan kurangnya rasa percaya diri, kurangnya kualitas tidur karena rasa gatal yang dialami dan terganggunya kenyamanan belajar (Fadilah, 2015).

Rentang usia 3-12 tahun dipilih karena menurut Albashtawy dan Hasna (2012) usia 3-12 tahun rentan sekali terjadi dan umumnya terjadi dikalangan anak. Semakin tinggi usia seseorang maka resiko terkena edikulosis akan semakin berkurang (Akib et al., 2017). Hal ini berbeda dengan penelitian Gulgun (2013) menyatakan bahwa pedikulosis menyerang anak-anak usia 5-16 tahun. Kejadian pedikulosis sebagian besar terjadi pada anak-anak usia sekolah (Lukman et al., 2018).

Angka prevalensi pedikulosis di salah satu perumahan Cibitung Bekasi lebih tinggi pada anak perempuan. Penelitian ini sesuai dengan penelitian sebelumnya di Pondok Pesantren Miftahul Ulum Kabupaten Jember, tingkat kejadian pedikulosis dari 287 anak usia 13-17 tahun, yang positif Pediculosis capitis sebesar 98,5\% dari 202 anak perempuan dan 17,6\% dari 85 anak laki-laki yang positif Pediculosis capitis (Lukman et al., 2018).

Penelitian ini dilengkapi data kuesioner mengenai faktor resiko pedikulosis. Kuesionernya terdiri dari jenis rambut, ukuran rambut, pemakaian handuk secara bersama, keramas seminggu $>2 \mathrm{x}$, keramas menggunakan sampo, anggota keluarga sebelumya pernah mengalami pedikulosis, rutinitas mengganti sprei tempat tidur seminggu sekali, penggunaan tempat tidur secara bersama, penggunaan sisir bersama, penggunaan aksesoris bersama dan pernah memakai obat kutu rambut.

Rutinitas mencuci rambut tidak memiliki pengaruh besar terhadap kejadian pedikulosis. Hal ini berbeda dengan penelitian Albashtawy dan Hasnah (2012) menyatakan bahwa rutinitas mencuci rambut berhubungan dengan tingkat kebersihan rambut dan kulit kepala karena semakin sering mencuci rambut maka akan mengurangi resiko terjadinya pedikulosis. Tingginya kejadian pedikulosis ini didukung dari kebiasaan keramas yang tidak menggunakan sampo. Dari 44 responden, 30 responden tidak menggunakan sampo dan 28 responden diantaranya positif pedikulosis. 
Penelitian yang telah dilakukan berdasarkan hasil kuesioner jenis rambut lurus menunjukan bahwa responden anak perempuan yang positif pedikulosis 93\% dari 29 anak perempuan. Anak laki-laki dengan rambut lurus yang positif pedikulosis $40 \%$ dari 5 anak laki-laki. Anak perempuan memiliki potensi pedikulosis yang tinggi dibandingkan anak laki-laki dengan jenis rambut lurus. Pediculus humanus capitis mampu hidup pada rambut yang lurus, ikal atau keriting (Fadilah, 2015). Penelitian pedikulosis di Jatinangor menyatakan bahwa Pediculus humanus capitis sering dijumpai di rambut keriting karena rambut yang keriting lebih lembab dibandingkan dengan rambut lurus (Karimah et al., 2016).

Berdasarkan hasil kuesioner mengenai riwayat keluarga yang pernah mengalami pedikulosis menunjukan anak perempuan memiliki potensi pedikulosis yang tinggi dibandingkan dengan anak laki-laki. Anak perempuan yang positif pedikulosis $83 \%$ dari 23 anakperempuan dan anak laki-laki yang positif pedikulosis 17\% dari 6 anak perempuan. Riwayat keluarga yang pernah mengalami pedikulosis memiliki peran yang tinggi terhadap kejadian pedikulosis. Pedikulosis dapat menular melalui kontak langsung antara kepala atau melalui penggunaan barang-barang secara bersama seperti sisir, bantal, kerudung, handuk dan tidur bersama (Aditya et al., 2013).

Responden yang tidak mengganti sprei tempat tidur seminggu sekali menunjukan anak perempuan yang positif pedikulosis $89 \%$ dari 28 anak perempuan dan anak laki-laki yang positif pedikulosis $60 \%$ dari 5 anak laki-laki. Penggunaan tempat tidur secara bersama menunjukan bahwa anak perempuan yang positif pedikulosis $89 \%$ dari 18 anak perempuan dan anak laki-laki yang positif pedikulosis 33\% dari 9 anak lakilaki. Menurut Rahman dan Malik (2014) menyatakan bahwa penggunaan alas atau tempat tidur bersama memicu terjadinya pedikulosis karena berbagi bantal atau tempat tidur mempermudah kutu rambut pindah secara langsung melalui kontak antara kepala dengan kepala yang saling berdekatan. Penggunaan sisir secara bersama menunjukan anak perempuan yang positif pedikulosis $86 \%$ dari 29 anak perempuandan anak laki-laki yang positif pedikulosis $43 \%$ dari 7 anak laki-laki. Penggunaan aksesoris secara bersama yang positif pedikulosis $90 \%$ dari 21 anak perempuan, sedangkan anak laki-laki tidak ada yang mengalami pedikulosis. Penggunaan sisir atau aksesoris rambut secara bersama akan menyebabkan tertularnya pedikulosis karena Pediculus humanus capitis bisa berpindah atau berjalan memalui perantara seperti sisir atau aksesoris rambut lainnya (Rahman dan Malik, 2014). Responden dengan riwayat pernah memakai obat kutu rambut tetapi masih mengalami pedikulosis, hal ini disebabkan pemakaian obat kutu rambut yang kurang efektif karena penderita kurang memperhatikan faktor resiko yang memicu terkena pedikulosis.

\section{KESIMPULAN}

Hasil penelitian ini dapat disimpulkan bahwa dari persentase angka kejadian pedikulosis pada 44 anak usia 3-12 tahun salah satu perumahan di Cibitung Bekasi adalah 28 anak perempuan dengan persentase $85 \%$ dari 33 anak perempuan dan 4 anak laki-laki dari 11 anak laki-laki dengan persentase $36 \%$.

\section{REFERENSI}

Aditya, Menaldi, \& Sungkar. 2013. Tingkat Pengetahuan mengenai Pemberantasan Pedikulosis di Pesantren X Jakarta Timur dan Sesudah Penyuluhan.Jurnal Kedokteran Indonesia (1). 53-57.

Akib, N., Sabilu, Y., \& Fachlevy, A. F. 2017. Studi Epidemiologi Penyakit Pediculosis capitis Pada Siswa Sekolah Dasar Negeri 08 Moramo Utara Kabupaten Konawe Selatan Sulawesi Tenggara. Jimkesmas(5), 1-11.

Albashtawy, M., \& Hasnah, F. 2012. Pediculosis capitis Among Primary-School Children in Mafraq Governorate Jordan. Eastrern Mediterranean Health Journal La Revue de Sante de la Mediterraneorientale, 18, 30-43.

[CDC] Center for Disease Control and Prevention. 2017. Retrieved November 28, 2018, from cdc.gov/eid:https://www.cdc.gov/dpdx/pediculosis. Eliska

Eliska, N. 2015. Retrieved from dokument.tips/dokuments/pedikulosiskapitis:http://dokument.tips/dokuments/pedikulosis-kapitis-55f3076e6d4a3.html

Fadilah, H. 2015. Perbedaan Metode Ceramah dan Leaflet Terhadap Skor Pengetahuan Santriwati Tentang Pediculosis capitis di Pondok Pesantren Al-Mimbar Sambongdukuh Jombang.

Gulgun, M., Balci, E., Kraoglu, A., Babacan, O., \& Turker, T. 2013. Pediculosis capitis Prevalence and ist Associated Factors in Primary School Chilidren Living in Rural and Urban Areas in Kayseri Turkey. Journal of Public Health, 21, 104108.

Hadidjaja, P., \& Margono. 2011. Dasar Parasitologi Klinik. Jakarta: FKUI. 
Haghi, F. M., Golchin, M., Yousefi, M., Hosseini, M., \& Parsi, B. 2014. Prevalence of Pediculosis and Associated Risk Fctors in the Girls Primary School in Azadshahr City Golestan Province. Journal of Health Sciences, 2, 63-68.

Irianto, K. 2013. Parasitologi Medis. Bandung: Alfabeta

Lukman, N., Armiyanti, Y., \& Agustina, D. 2018. Hubungan Faktor-Faktor Risiko Pediculosis capitis terhadap Kejadianya pada Santri di Pondok Pesantren Miftahul Ulum Jember. Jurnal Agromedicine and Medical Sciences, 4, 102-109.

Maryanti, E., Lesmana, S. D., \& Novira, M. 2018. Hubungan Faktor Risiko denga Infestasi Pediculus humanus capitis pada Anak Panti Asuhan di Kota Pekanbaru. Jurnal Kesehatan Melayu, 1, 73-80.

Natadisastra, D., \& Agoes, R. 2014. Parasitologi Kedokteran Ditinjau dari Organ Tubuh yang Diserang. Jakarta: EGC.

Nurlatifah, I., Astuti, R. I., \& Indrasari, E. R. 2017. Hubungan Usia, Jenis Kelamin, Sosial Ekonomi, dan Higiene dengan Kejadian Pediculosis capitis. Jurnal Pendidikan Dokter, 3, 574-580.

Rahman, Z. A., \& Malik, D. A. 2014. Faktor-Faktor yang Berhubungan Dengan Kejadian Pediculosis capitis Pada Santri Pesantren Rhodlotul Quran Semarang. Tesis. Saide, P. M., Pavia, N., Buenfil, J. R., Herrera, R. H., Ruiz, P. G., \& Pilger, D. 2011.

Soedarto. 2016. Buku Ajar Parasitologi Kedokteran (2nd ed.). Jakarta: Sagung Seto.

Tohit, F. M., Rampal, L., \& Sann-Mun, L. 2017. Prevalence and predictors of pediculosis capitis among primary school children in Hulu Langat Selangor. Department of Community Health, 12-17.

Wolff, K., \& Richard, A. J. 2009. Color Atlas and Synopsis of Clinical Dermatology. USA: Mc Graw-Hill. 